Article

\title{
The Cytotoxic Effect of Genistein, a Soybean Isoflavone, against Cultured Tribolium Cells
}

\author{
Shingo Kikuta $\mathbb{D}$ \\ College of Agriculture, Ibaraki University, Ami, Ibaraki 300-0393, Japan; shingo.kikuta.pes@vc.ibaraki.ac.jp; \\ Tel.: +81-29-888-8561
}

Received: 28 February 2020; Accepted: 9 April 2020; Published: 12 April 2020

\begin{abstract}
The red flour beetle Tribolium castaneum is a known pest of various grains and stored-products such as wheat flours; however, T. castaneum feeds on and infests soybean and soy products. For more than 60 years, soy flour has been suggested to be unstable food for Tribolium spp. because it causes larval development failure. However, it remains unknown whether soy flour affects adult beetles. The objective of the present study was to examine the effects of soy flour and its related isoflavones against $T$. castaneum using an artificial dietary intake assay. Beetles were fed gypsum (a non-digestible compound) mixed with either water (control) or soy flour. Significantly fewer beetles survived after being fed the soy flour treatment. Although the soy isoflavone genistein, a defensive agent and secondary metabolite, decreased the T. castaneum adult survival, it required a long time to have a lethal effect. Therefore, the cytotoxic effects of soy flour, i.e., the rapid biological responses following isoflavone addition, were also examined using a cultured cell line derived from T. castaneum. Both genistin and genistein significantly affected the survival of the cultured cells, although genistein had a stronger lethal effect. This study demonstrated the toxicity of genistein found in soybean against T. castaneum cultured cells within $24 \mathrm{~h}$ period. Genistein may be used as an oral toxin biopesticide against $T$. castaneum.
\end{abstract}

Keywords: cultured cell; Tribolium castaneum; isoflavone; cell toxicity; Tc81 cells

\section{Introduction}

The red flour beetle Tribolium castaneum (Herbst) is a serious stored-grain pest that attacks various foods, such as wheat flour, dried fruits, nuts, pasta, cereal germs, and processed foods [1,2]. The dietary intake of adult $T$. castaneum beetles is activated by carbohydrates, such as fructose, sucrose, and mannitol [3]. Whole-wheat flour contains these sugars as its major carbohydrates; therefore, wheat flour constitutes a suitable food source for T. castaneum beetles. The confused flour beetle Tribolium confusum (Jacquelin du Val), a beetle species that is very similar in appearance to T. castaneum, also attacks and infests peas as well as stored-grains and associated products; however, it has rarely been identified as a pest of soybean and soy products [4]. In previous studies, both the larvae of $T$. confusum and $T$. castaneum did not develop to pupal and adult stages when fed on soy flour, thus resulting in a decreased number of larval instars in their development $[5,6]$. In addition, another study demonstrated that the fecundity of $T$. castaneum females was markedly decreased when they were fed soy flour [7]. Compared with whole wheat flour, soy flour is an unsuitable food source for T. castaneum and T. confusum [7-9]. However, the causes of larval development failure and the effects of soy flour on adult beetles remain unknown. Soy and its flour contain high protein and low carbohydrate contents [10]. In contrast, wheat flour is mainly composed of carbohydrates but also contains moderate amounts of protein [11,12]. Given that wheat flour is a preferable food for T. castaneum, carbohydrates appear to be an important nutritional factor [3]. However, the absence of carbohydrates in the diet have not been shown to lead to an increase in beetle mortality and immature 
development [13]. Some ingredients in soy flour have been shown to have lethal effects against T. castaneum. The present study examined the insecticidal effects of flavonoids that occur naturally in plants as candidate toxic insecticides against $T$. castaneum.

Secondary metabolites, such as flavonoids and isoflavonoids, especially isoflavones, saponins, and phenolic acids, play important roles in plant-insect interactions as defensive agents [14-17]. High doses of two polyphenolic flavonoids, luteolin and genistein, have been shown to repulse Acyrthosiphon pisum due to their antifeedant and toxic effects [18,19]. Soybean contains 12 isoflavones including three aglycones: genistein, daidzein, and glycitein, which accumulate in response to insect herbivores and UV exposure [20,21]. Soybean extracts containing genistin, a major flavonoid, reduced the larval and pupal weight of Anticarsia gemmatalis [22]. Flavonoids and isoflavones contained in soy flour may affect $T$. castaneum. The effects of these flavonoids on T. castaneum adults need to be evaluated via their addition to an artificial diet. Until now, the toxic effects on T. castaneum have previously been examined using dried flour-based artificial diets combined with insecticides [7,23]; however, this approach is limited in its use in evaluating preferences because the organic compounds in flour cannot be completely separated. A novel artificial dietary intake assay involving the use of gypsum blocks, designated the TribUTE (Tribolium Urges To Eat) assay, can be used to estimate the effects of substances of interest without the addition of organic compounds [24,25]. This study aimed to elucidate if soy flour and its associated flavonoids affect $T$. castaneum adults using the TribUTE system. In addition, this study also examined the cytotoxic effects of soybean-derived isoflavones using a cultured cell line derived from $T$. castaneum to better understand the rapid biological responses of $T$. castaneum to soybean extracts. The objectives of the present study were to examine the effects of soy flour and isoflavones against $T$. castaneum using the TribUTE assay and cultured cells.

\section{Materials and Methods}

\subsection{Insects}

Tribolium castaneum (Herbst) were maintained following a previous study [25]. Briefly, T. castaneum were maintained with feed comprising whole-wheat flour (Tomiz Co. Ltd., Tokyo, Japan) mixed with $5 \%$ yeast (Saf-instant ${ }^{\circledR}$, Lesaffre, Marcq-en-Baroeul, France) at $25 \pm 1{ }^{\circ} \mathrm{C}$ and $70 \%$ relative humidity under a 16:8 h light: dark cycle. Female adults (1-2 weeks old) were maintained in a cage and starved for 5 days prior to use.

\subsection{Cell Culture}

The T. castaneum cultured cell line, Tc81, was grown in IPL-41 insect medium (Thermo Fisher Scientific, Carlsbad, CA, USA) supplemented with $10 \%$ fetal bovine serum (FBS, Thermo Fisher Scientific, Carlsbad, CA, USA) at $25^{\circ} \mathrm{C}$. Cell cultures were maintained following a previous study [26]. Briefly, the Tc 81 cells proliferated inside vesicles. After culturing, the huge vesicles were broken by pipetting. One-third of the medium was replaced with fresh medium once a week. The number of cells in the vesicles were calculated using a cell counting chamber (Thermo Fisher Scientific, Carlsbad, CA, USA) prior to the experiments.

\subsection{Isoflavones and Organic Compounds}

The test isoflavones were obtained from FUJIFILM Wako Pure Chemicals (Tokyo, Japan). Daidzin, daidzein, glycitin, glycitein, genistin, and genistein were dissolved in dimethyl sulfoxide (DMSO, Tokyo Chemical Industry, Tokyo, Japan) and aliquots were added to the cell culture microplates (Trueline, Nippon Genetics, Tokyo, Japan). The final concentrations of DMSO in the insect culture medium were kept below $1 \%(\mathrm{v} / \mathrm{v})$. Whole wheat flour and soy flour were obtained from a local retail store (Ami, Ibaraki, Japan). The test flours and gypsum powder were mixed at a ratio of 1:5 (w/w). 


\subsection{Dietary Intake Assay}

The dietary intake assay, i.e., the TribUTE assay, was performed as described previously [3,24]. Briefly, the control artificial diet consisted of gypsum and water, i.e., it contained almost no digestible organic compounds and was considered to be the treatment with the lowest nutrient component. The gypsum block consumed by the T. castaneum adults was eventually excreted without digestion as a waste product that could be measured. The gypsum was labeled with the fluorescence dye ROX (TaKaRa Bio, Shiga, Japan) as an endogenous tracer to enable quantification of the gypsum excreta, which was based on the intensity emitted by ROX and measured using the fluorescence microplate reader Synergy ${ }^{\mathrm{TM}}$ HTX (BioTek Japan, Tokyo, Japan). T. castaneum adults were individually fed the treatment gypsum blocks, and maintained at $25 \pm 1{ }^{\circ} \mathrm{C}$ and $70 \%$ relative humidity under a $16 \mathrm{~L}: 8 \mathrm{D}$ cycle. The experiments were independently performed three times, and representative data are shown here.

\subsection{Survival of T. Castaneum Adults}

Gypsum diet blocks ( $5 \mathrm{~mm})$ were supplemented with wheat flour, soy flour, or water. Blocks were individually fed to T. castaneum adults and maintained in individual wells on 24-well microplates. The set of microplates were kept at $25 \pm 1^{\circ} \mathrm{C}$. The number of dead beetles was scored daily until 8 days after the treatment. Statistical significance was determined using a log-rank (Mantel-Cox) test and Prism 7 software (GraphPad, San Diego, CA). The survival assays were repeated at least three times as biological replicates, and representative data are shown here.

\subsection{Cell Survival and Cytotoxicity Assay}

Alive Tc81 cells were counted using the WST-8 colorimetric assay [2-(2-methoxy-4-nitrophenyl)-3(4-nitrophenyl)-5-(2, 4-disulfophenyl)-2H-tetrazolium, Dojindo, Kyoto, Japan]. Dead cells were counted using colorimetry based on the LDH (lactate dehydrogenase) assay (Dojindo). Absorbance was measured using a microplate reader at $450 \mathrm{~nm}$ and $495 \mathrm{~nm}$. The experimental procedures were conducted according to the protocols of the manufacturers, with a minor adjustment of the enzyme reaction temperature, i.e., $25^{\circ} \mathrm{C}$ was used [27]. The significance of the cell survival rates was determined using a Kruskal-Wallis test and post-hoc Dunn's multiple comparisons test. The Tc81 cells were also observed under an inverted microscope at $24 \mathrm{~h}$ after the treatments. The experiments were conducted with each concentration and isoflavone in triplicates. All bioassays were repeated at least three times as biological replicates, and representative data are shown here.

\section{Results}

\subsection{Dietary Intake of Gypsum Supplemented with Soy Flour by T. Castaneum}

The dietary intake was estimated by measuring gypsum excreta based on the TribUTE assay (Figure 1). The amount of gypsum excreta was higher in the soy flour treatment compared with the control treatment. These findings indicated that T. castaneum adult beetles recognized and digested gypsum-containing soy flour.

\subsection{Lifespan of T. Castaneum Adults Supplemented with Soy Flour and Isoflavone}

The number of alive beetles were counted daily (Figure 2). Significantly fewer beetles survived after being fed the gypsum and soy flour treatment compared with the control treatment, and the survival of T. castaneum markedly decreased from 6 to 8 days. Soy flour did not extend the lifespan of T. castaneum. These results also indicated that the T. castaneum beetles were affected by certain toxins in soy flour rather than by the nutritional contents. 


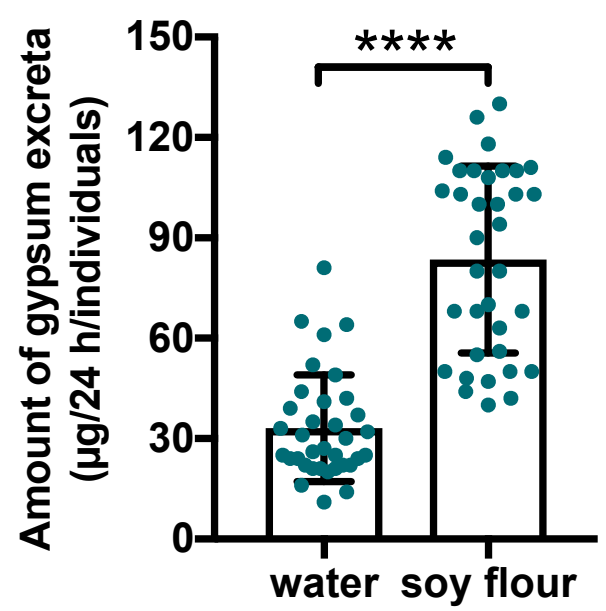

Figure 1. Quantification of gypsum excreta from Tribolium castaneum. Thirty-five beetles were examined in this assay for each treatment. The gypsum feces excreted by individual beetles within a $24 \mathrm{~h}$ period were weighed using a microbalance (green dots). Statistical significance was determined using the Mann-Whitney U test $\left.{ }^{* * * *} p<0.0001\right)$. Each statistical value is shown in Supplemental data. Error bars represent S.D. Water: the adults were fed gypsum supplemented with water as the control. Soy flour: the adults were fed gypsum supplemented with soy flour.

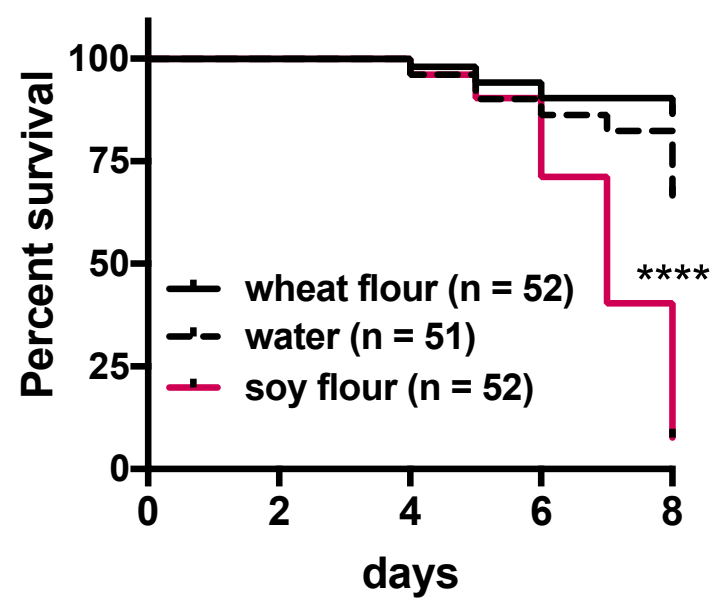

Figure 2. Survival of Tribolium castaneum adults fed a gypsum diet supplemented with soy flour. Each beetle was fed a gypsum diet supplemented with either wheat flour, water (control), or soy flour. The effects of the supplements on the lifespan of T. castaneum adults were assessed using the survival rate of female adult beetles. Statistical significance was determined using the log-rank (Mantel-Cox) test $\left.{ }^{* * * *} p<0.0001\right)$ and the Gehan-Breslow-Wilcoxon test. Each statistical value is shown in Supplemental data.

The present study assessed the effect of isoflavones, such as daidzin, daidzein, glycitin, glycitein, genistin, and genistein, on T. castaneum beetles by TribUTE assay (Figure 3). Daidzin, glycitin, glycitein, and genistin were not found to have lethal effects on the beetles. Daidzein had a minor lethal effect. The survival rates of beetles significantly decreased in the presence of $20 \mu \mathrm{M}$ genistein and genistin (Figure 3). Genistein, a major flavonoid in soy flour, greatly affected T. castaneum; however, the assessment of its effects required the monitoring of the survival rates of female adults for 7 days after exposure. In addition, genistein did not appear to have a lethal effect for a short period of time (data not shown). Therefore, it was difficult to identify the effects by isoflavones, including genistein, using the TribUTE assay. 


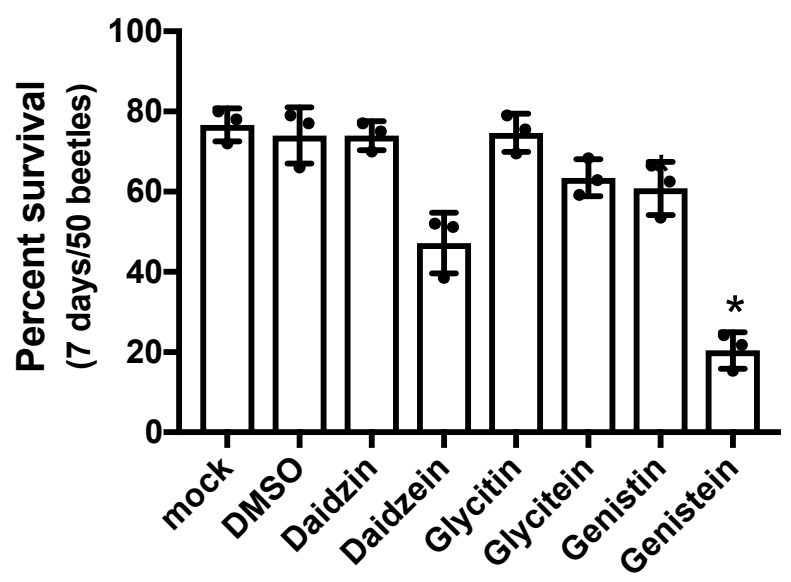

Figure 3. Survival of Tribolium castaneum adults fed diets supplemented with isoflavones. Adult beetles were fed gypsum blocks containing different isoflavones. Survival rates were estimated 7 days after exposure. Fifty beetles were examined per treatment, and experiments were conducted in triplicate. Mock: the gypsum block was supplemented with water only. DMSO was utilized as the solvent. Isoflavones were added to the gypsum blocks at $25 \mu \mathrm{M}$. Statistical significance was determined using the Kruskal-Wallis test $\left({ }^{* *} p=0.007\right)$ and Dunn's multiple comparisons test $\left({ }^{*} p=0.0104\right)$. Each statistical value is shown in Supplemental data.

\subsection{Cytotoxicity of Tc81 Cultured Cells by Isoflavones}

The Tc81 cells were exposed to media containing each isoflavone for $24 \mathrm{~h}$ (Figure 4). DMSO was used as a solvent of the isoflavonoids. DMSO did not affect the Tc81 cells, compared with the control treatment (i.e., with no additives) (Figure 4A,B). Daidzin, daidzein, glycitin, and glycitein had minor lethal effects on the Tc81 cells (Figure 4C-F, respectively). Genistin had an evident cytotoxic effect on the Tc81 cells, whereby the Tc81-containing vesicles shrunk (Figure 4G). Genistein had a major cytotoxic effect on the Tc81 cells, whereby the Tc81-containing vesicles were also damaged (Figure $4 \mathrm{H}$ ). These results indicated that genistein affected the Tc81 cells as well as the Tribolium adults.

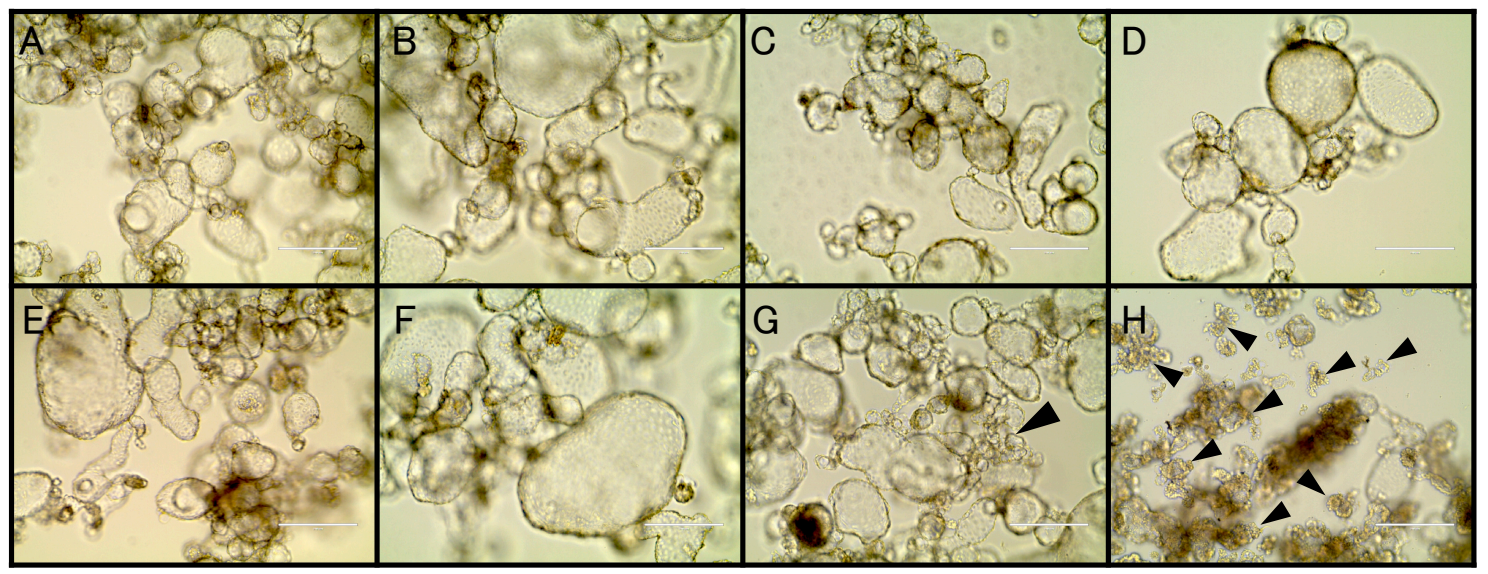

Figure 4. Cytotoxicity of Tc81 cultured cells by isoflavones after exposure for $24 \mathrm{~h}$. The Tc81 cells were exposed to $20 \mu \mathrm{M}$ of the different isoflavones in the culture medium. (A) mock (control); (B) DMSO; (C) Daidzin; (D) Daidzein; (E) Glycitin; (F) Glycitein; (G) Genistin; (H) Genistein. Scale bars represent $200 \mu \mathrm{m}$. Arrows (black) indicate shrunken cells.

\subsection{Colorimetry Based Cell Viability Assay for Tc81 Cells}

The viability of Tc81 cells exposed to isoflavones was examined using WST-8 at $24 \mathrm{~h}$ after exposure. Significant Tc81 viability was observed in the presence of daidzin, daidzein, glycitin, and glycitein. However, compared to the DMSO control level, viability decreased when cells were exposed to genistin 
and genistein in the culture medium (Figure 5A). Both genistin and genistein significantly affected the survival of the Tc81 cells, but genistein had a stronger lethal effect. The lethality of the Tc81 cells was examined using an LDH assay. The lethal concentration $\left(\mathrm{LC}_{50}\right)$ of genistein was $12.7 \pm 0.9 \mu \mathrm{M}$ for $24 \mathrm{~h}$.

A

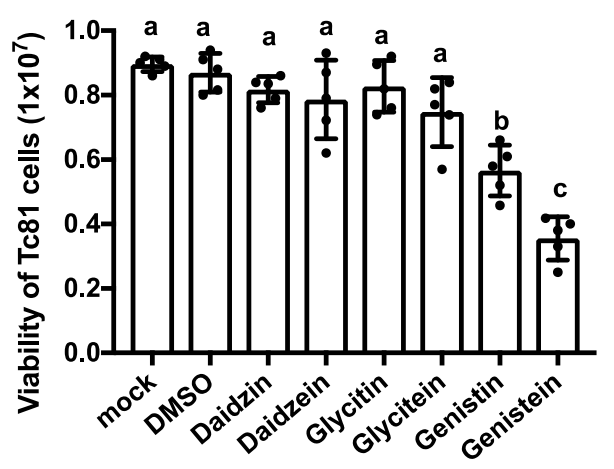

B

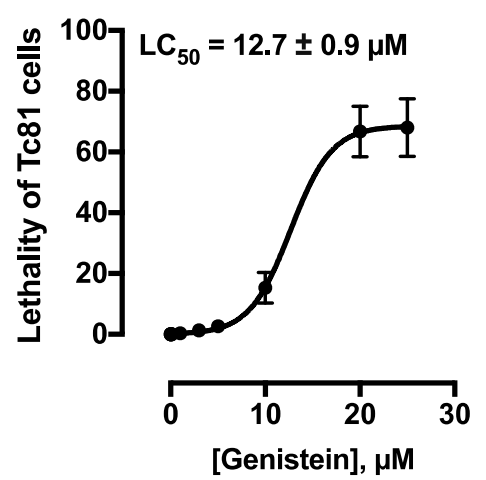

Figure 5. Cytotoxicity of Tc81 cells in the presence of isoflavones. (A) The survival of Tc81 cells was examined at $24 \mathrm{~h}$ after exposure. Cell viability was evaluated using 24-microwell plates, and each dot represents an individual well. Statistical significance was determined using the Kruskal-Wallis test $\left.{ }^{* * *} p=0.0003\right)$ and Dunn's multiple comparisons test. Same letters indicate non-significance. Each statistical value is shown in Supplemental data. (B) Lethal concentration response assessment of Tc81 cells against genistein. The lethality was examined at $24 \mathrm{~h}$ after exposure. Error bars represent S.E.

\section{Discussion}

For over 60 years, studies have shown that soy flour is an unstable food for Tribolium spp. because the larval growth rates of T. castaneum and T. confusum fed only soy flour were significantly delayed compared to those fed whole wheat flour supplemented with yeast [5,6]. However, to date, the reason for soy extracts resulting in high mortality rates and poor growth in T. castaneum remains unclear. Despite the willingness of T. castaneum adults and larvae to consume soy flour (Figure 1), the nutritional content of this food source appears to be markedly insufficient for the growth of the species as well as that of T. confusum larvae compared with whole wheat flour (Figure 2). Soy flour did not contribute to the lifespan of T. castaneum. Rather, the T. castaneum beetles seemed to be affected by certain toxins in soy flour. The present study examined the insecticidal effects of flavonoids that occur naturally in plants as candidate toxic insecticides against T. castaneum. Many flavone and isoflavone derivatives have been identified in the soybean plant [28]. Plants including soybean synthesize secondary metabolites such as phenols, saponins, flavonoids, alkaloids, terpenoids, and others, as part of their defenses against herbivory [16]. In insects, flavonoids interfere with several steps of their behaviors, such as molting, feeding, and reproduction [29]. Some flavonoids have been shown to have toxic effects against Diabrotica virgifera virgifera and Spodoptera litura [30,31]. Soy flour contains several flavonoids including agricons, which were expected to interfere with the survival of T. castaneum beetles. Although the TribUTE assay was able to show the effects against T. castaneum adults (Figure 3), it required a long time to demonstrate the lethality of test substances compared with the evaluation system using cultured cells.

The present study also examined the cytotoxic effect of isoflavones using the T. castaneum cultured cell line Tc81 (Figure 4). Insect cultured cells have been established for several species to analyze their biochemical responses, which is valuable for the development of efficient screening systems to discover new drugs and functional chemicals, including insecticides [26,32,33]. For example, the cytotoxicity of $\beta$-asarone, the essential oil of rhizomes derived from Acorus calamus, was evaluated using the Spodoptera frugiperda cell line Sf9 [34]. Owing to the difficulty in identifying the effects of isoflavones using the TribUTE assay and adult T. castaneum beetles in the present study, I decided to assess the lethal effects of these compounds using insect cultured cells. The Tc81-containing vesicles shrunk under genistin and genistein $24 \mathrm{~h}$ after exposure. It was unclear whether the genistein cytotoxicity directly affected the 
Tc81 cells or indirectly affected the cells via the vesicle disruptions. The viability and lethality of Tc81 cells were then examined using the WST-8 colorimetric assay and the LDH assay (Figure 5). Actually, both genistin and genistein significantly affected the survival of the Tc 81 cells, although genistein had a stronger lethal effect. The present study concluded that genistein exhibited a significant lethal effect in isoflavones tested against T. castaneum. Glycoside derivatives of daidzein and genistein and acetate derivatives have been shown to have toxic effects on the larvae of mosquito, e.g., the $\mathrm{LC}_{50}$ value of genistein for mosquito larvae was $40 \mu \mathrm{M}$ [35]. The findings of the present study are consistent with those the previous study on mosquito larvae (Figure 5B), thus suggesting that genistein may be an active toxic component in plants and may be used as a biopesticide against insects. Soya is not the only one with this potential for plant insecticidal activity. Thus far, it has been shown that many stored-product insects and mites cannot develop in legume seeds [36]. These toxic effects were also provided by the proteins contained in it, implying that other compounds contained in legume seeds could cause lethality against $T$. castaneum adults. The most effective toxic component in soya will become a biopesticide candidate. The cultured Tc 81 cells are available to conduct chemical screening.

Several studies have shown that genistein, a secondary plant metabolite, can have deterrent or lethal effects on polyphagous insects $[19,22,35]$. For example, high genistein levels decreased the sucking efficiency of A. pisum [37]. Genistein, however, has numerous health benefits for humans, e.g., it reduces the risk of cardiovascular disease and prevents the proliferation of breast cancer cells [38-41]. In addition, genistein acts as an agonist that binds to estrogen receptors in mammals [42]. T. castaneum also expresses an estrogen-like receptor, however, the function of such receptors remains unclear. Given that genistein had a lethal effect on Tc 81 cells in the present study, these insect cultured cells may become a useful tool for studying certain mechanisms, e.g., regarding these estrogen-like receptors. Collectively, the findings of the present study and those of previous studies indicate that genistein may have multiple functions, and that these functions may be species-dependent.

\section{Conclusions}

The present study demonstrated the toxicity of isoflavone genistein found in soybean against T. castaneum and its cultured cells. The present findings that genistein has a cytotoxic effect on Tc81 cultured cells will help to elucidate the mechanisms underlying soy-stored insect interactions. Secondary metabolites such as phenols, saponins, and flavonoids are synthesized by plants after perceiving herbivore attacks. These natural chemicals in plants show various properties of repellents, feeding deterrents, growth retardants, and toxicants against insects, and thus they may have commercial applications as botanical insecticides for crop protection [43]. Isoflavonoids, including genistein, have excellent potentials as naturally occurring insecticides and as alternatives to chemical-based insecticides in the management of T. castaneum. My findings indicated that genistein may act as an oral toxin and biopesticide against $T$. castaneum. Further studies are required to assess the interactions of other stored-grain pests and soy compounds.

Supplementary Materials: The following are available online at http://www.mdpi.com/2075-4450/11/4/241/s1.

Funding: This research was partially supported by Fuji Foundation for Protein Research. The funders had no role in study design, data collection and analysis, decision to publish, or preparation of the manuscript.

Acknowledgments: Tc81 cells were provided by the Genetic Resources Center, NARO (Tsukuba, Japan).

Conflicts of Interest: The author declares no conflict of interest.

\section{References}

1. LeCato, G.L. Red flour beetle: Population growth on diet of corn, wheat rice or shelled peanuts supplemented with eggs or adult of the Indian meal moth. J. Econ. Entomol. 1975, 68, 763-765. [CrossRef]

2. Hagstrum, D. Atlas of Stored-Product Insects and Mites, 1st ed.; Elsevier: Amsterdam, The Netherlands, 2013; ISBN 9780128104316. 
3. Takada, T.; Sato, R.; Kikuta, S. A mannitol/sorbitol receptor stimulates dietary intake in Tribolium castaneum. PLoS ONE 2017, 12, e0186420. [CrossRef] [PubMed]

4. Good, N.E. The flour beetles of the genus Tribolium. USDA Tech. Bul. 1936, 498, 1-57.

5. Lin, S.; Richard, G. Studies on the nutritional value of soybean flour to Tribolium confusum duv. J. N. Y. Entomol. Soc. 1952, 60, 107-118.

6. Mickel, C.E.; Standish, J. Susceptibility of Processed Soy Flour and Soy Grids in Storage to Attack by Tribolium castaneum (Herbst); University of Minnesota Agricultural Experiment Station: St. Paul, MN, USA, 1947; p. 178.

7. Sokoloff, A.; Franklin, I.R.; Overton, L.F.; Ho, F.K. Comparative studies with Tribolium (Coleoptera, Tenebrionidiae)-I: Productivity of T. castaneum (Herbst) and T. confusum Duv. On several commercial-available diets. J. Stored Prod. Res. 1966, 1, 295-311.

8. Naseri, B.; Borzoui, E.; Majd, S.; Mozaffar Mansouri, S. Influence of different food commodities on life history, feeding efficiency, and digestive enzymatic activity of Tribolium castaneum (Coleoptera: Tenebrionidae). J. Econ. Entomol. 2017, 110, 2263-2268. [CrossRef]

9. Astuti, L.P.; Rizali, A.; Firnanda, R.; Widjayanti, T. Physical and chemical properties of flour products affect the development of Tribolium castaneum. J. Stored Prod. Res. 2020, 86, 101555. [CrossRef]

10. Markley, K.S.; Goss, W.H. Soybean Chemistry and Technology; Chemical Publishing: New York, NY, USA, 1944; pp. 137-143.

11. Osborne, T.B.; Mendel, L.B. The nutritive value of the wheat kernel and its milling products. J. Biol. Chem. $1919,37,557-601$.

12. Taggart, P. Starch as an ingredient: Manufacture and applications. In Starch in Food Structure, Function and Applications; Eliasson, A.-C., Ed.; Woodhead Publishing: Cambridge, UK, 2004; pp. 363-392.

13. Fraenkel, G.; Blewett, M. The basic food requirements of several insects. J. Exp. Biol. 1943, 20, $28-34$.

14. Harborne, J.B. The Flavonoids: Advances in Research Since 1980; Springer US: New York, NY, USA, 1988; pp. 125-209.

15. Simmonds, M.S.; Stevenson, P.C. Effects of isoflavonoids from Cicer on larvae of Heliocoverpa armigera. J. Chem. Ecol. 2001, 5, 965-977. [CrossRef]

16. Kubo, I. New concept to search for alternate insect control agents from plants. In Naturally Occurring Bioactive Compounds, 1st ed.; Rai, M., Carpinella, M., Eds.; Elsevier: Amsterdam, The Netherlands, 2006; Volume 3 , pp. 61-80.

17. Hohenstein, J.D.; Studham, M.E.; Klein, A.; Kovinich, N.; Barry, K.; Lee, Y.J.; MacIntosh, G.C. Transcriptional and chemical changes in soybean leaves in response to long-term aphid colonization. Front. Plant Sci. 2019, 10, 310. [CrossRef] [PubMed]

18. Cox, P.D. Potential for using semiochemicals to protect stored products from insect infestation. J. Stored Prod. Res. 2004, 40, 1-25. [CrossRef]

19. Goławska, S.; Lukasik, I. Antifeedant activity of luteolin and genistein against the pea aphid, Acyrthosiphon pisum. J. Pest Sci. 2012, 85, 443-450. [CrossRef] [PubMed]

20. Shao, S.; Duncan, A.M.; Yang, R.; Marcone, M.F.; Rajcan, I.; Tsao, R. Tracking isoflavones: From soybean to soy flour, soy protein isolates to functional soy bread. J. Funct. Foods 2009, 1, 119-127. [CrossRef]

21. Zavala, J.A.; Mazza, C.A.; Dillon, F.M.; Chludil, H.D.; Ballare, C.L. Soybean resistance to stink bugs (Nezara viridula and Piezodorus guildinii) increases with exposure to solar UV-B radiation and correlates with isoflavonoid content in pods under field conditions. Plant Cell Environ. 2015, 38, 920-928. [CrossRef]

22. Piubelli, G.C.; Hoffmann-Campo, C.B.; Moscardi, F.; Miyakubo, S.H.; Neves De Oliveira, M.C. Are chemical compounds important for soybean resistance to Anticarsia gemmatalis? J. Chem. Ecol. 2005, 31, 1509-1525. [CrossRef]

23. Xie, Y.S.; Bodnaryk, R.P.; Fields, P.G. A rapid and simple flour-disk bioassay for testing substances active against stored-product insects. Can. Entomol. 1996, 128, 865-875. [CrossRef]

24. Kikuta, S. TribUTE-F assay: Fluorescence-based rapid quantification of dietary intake in the red flour beetle, Tribolium castaneum (Coleoptera: Tenebrionidae), facilitates evaluation of antifeedant inhibitory effects. J. Stored Prod. Res. 2018, 77, 122-125. [CrossRef]

25. Kikuta, S. Deployment of an attractive toxic sugar bait system (ATSB) with insecticide, for adult Tribolium castaneum (Coleoptera: Tenebrionidae). J. Stored Prod. Res. 2019, 83, 97-102. [CrossRef] 
26. Kayukawa, T.; Tateishi, K.; Shinoda, T. Establishment of a versatile cell line for juvenile hormone signaling analysis in Tribolium castaneum. Sci. Rep. 2013, 3, 1570. [CrossRef]

27. Tang, H.; Wu, Y.; Wu, H.; Wu, Y.; Wu, H.; Wang, W. Functional analysis of a survivin-like gene in Bombyx mori. Cytotechnology 2014, 1, 181-191. [CrossRef] [PubMed]

28. Caballero, P.; Smith, C.M.; Fronczek, F.R.; Fischer, N.H. Isoflavones from an insect-resistant variety of soybean and the molecular structure of afrormosin. J. Nat. Prod. 1986, 49, 1126-1129. [CrossRef]

29. Simmonds, M.S. Importance of flavonoids in insect-plant interactions: Feeding and oviposition. Phytochemistry 2001, 56, 245-252. [CrossRef]

30. Mullin, C.A.; Alfatafta, A.A.; Harman, J.L.; Everett, S.L.; Serino, A.A. Feeding and toxic effects of floral sesquiterpene lactones, diterpenes, and phenolics from sunflower on western corn rootworm. J. Agric. Food Chem. 1991, 39, 2293-2299. [CrossRef]

31. Morimoto, M.; Kumeda, S.; Komai, K. Insect antifeedant flavonoids from Gnaphalium affine D. Don. J. Agric. Food Chem. 2000, 48, 1888-1891. [CrossRef]

32. Smagghe, G.; Goodman, C.L.; Stanley, D. Insect cell culture and applications to research and pest management. In Vitro Cell. Dev. Biol. Anim. 2009, 45, 93-105. [CrossRef]

33. Silver, K.; Jiang, H.; Fu, J.; Phillips, T.W.; Beeman, R.W.; Park, Y. The Tribolium castaneum cell line TcA: A new tool kit for cell biology. Sci. Rep. 2014, 4, 6840. [CrossRef]

34. Yooboon, T.; Kuramitsu, K.; Bullangpoti, V.; Kainoh, Y.; Furukawa, S. Cytotoxic effects of $\beta$-asarone on Sf9 insect cells. Arch. Insect Biochem. Physiol. 2019, 102, e21596. [CrossRef]

35. Rao, K.V.; Chattopadhyay, S.K.; Reddy, G.C. Flavonoids with mosquito larval toxicity. J. Agr. Food Chem. 1990, 38, 1427-1430. [CrossRef]

36. Hubert, J.; Stejskal, V.; Aspaly, G.; Münzbergová, Z. Suppressive Potential of Bean (Phaseolus vulgaris) Flour Against Five Species of Stored-Product Mites (Acari: Acarididae). J. Econ. Entomol. 2014, 100, 586-590. [CrossRef]

37. Yuan, E.; Yan, H.; Gao, J.; Guo, H.; Ge, F.; Sun, Y. Increases in genistein in Medicago sativa confer resistance against the Pisum host race of Acyrthosiphon pisum. Insects 2019, 10, 97. [CrossRef] [PubMed]

38. Wang, T.T.; Sathyamoorthy, N.; Phang, J.M. Molecular effects of genistein on estrogen receptor mediated pathways. Carcinogenesis 1996, 2, 271-275. [CrossRef] [PubMed]

39. Rimbach, G.; Boesch-Saadatmandi, C.; Frank, J.; Fuchs, D.; Wenzel, U.; Daniel, H.; Hall, W.L.; Weinberg, P.D. Dietary isoflavones in the prevention of cardiovascular disease-A molecular perspective. Food Chem. Toxicol. 2008, 46, 1308-1319. [CrossRef] [PubMed]

40. Yuan, B.; Wang, L.; Jin, Y.; Zhen, H.; Xu, P.; Xu, Y.; Li, C.; Xu, H. Role of metabolism in the effects of genistein and its phase II conjugates on the growth of human breast cell lines. AAPS J. 2012, 14, 329-344. [CrossRef]

41. Chatterjee, G.; Roy, D.; Khemka, V.K.; Chattopadhyay, M.; Chakrabarti, S. Genistein, the isoflavone in soybean, causes amyloid beta peptide accumulation in human neuroblastoma cell line: Implications in Alzheimer's disease. Aging Dis. 2015, 6, 456-465. [CrossRef]

42. Dang, Z.C.; Audinot, V.; Papapoulos, S.E.; Boutin, J.A.; Löwik, C.W. Peroxisome.proliferator-activated receptor gamma (PPARgamma) as a molecular target for the soy phytoestrogen genistein. J. Biol. Chem. 2003, 278, 962-967. [CrossRef]

43. Hikal, W.M.; Baeshen, R.S.; Said-Al Ahl, H.A. Botanical insecticide as simple extractives for pest control. Cogent Biol. 2017, 3, 1404274. [CrossRef]

(C) 2020 by the author. Licensee MDPI, Basel, Switzerland. This article is an open access article distributed under the terms and conditions of the Creative Commons Attribution (CC BY) license (http://creativecommons.org/licenses/by/4.0/). 